\title{
Challenge in Enhancing the Teaching and Learning of Variable Measurements in Quantitative Research
}

\author{
Chang Peng Kee ${ }^{1}$, Kamisah Osman ${ }^{2} \&$ Fauziah Ahmad ${ }^{1}$ \\ ${ }^{1}$ School of Media and Communication Studies, Faculty of Social Sciences and Humanities, The National \\ University of Malaysia, Malaysia \\ ${ }^{2}$ Learning and Teaching Innovation Department, Faculty of Education, The National University of Malaysia, \\ Malaysia \\ Correspondence: Chang Peng Kee, School of Media and Communication Studies, Faculty of Social Sciences and \\ Humanities, The National University of Malaysia, 43600 UKM Bangi, Malaysia. Tel: 60-389-214-703. E-mail: \\ chang@ukm.my
}

Received: February 7, 2013 Accepted: March 26, 2013 Online Published: May 13, 2013

doi:10.5539/ies.v6n6p15 URL: http://dx.doi.org/10.5539/ies.v6n6p15

The research is financed by UKM-PTS-052-2009, Centre for Academic Advancement, The National University of Malaysia.

\begin{abstract}
Statistical analysis is one component that cannot be avoided in a quantitative research. Initial observations noted that students in higher education institution faced difficulty analysing quantitative data which were attributed to the confusions of various variable measurements. This paper aims to compare the outcomes of two approaches applied in enhancing the quality of teaching and learning statistics. 143 communication undergraduate students were involved as participants in this action research. They were divided into two groups, in which one experienced "group quiz" technique and the other went through the newly designed "challenge the challenger" technique. The effects of interventions given were measured from the students' cognitions of variable measurements before and after such interventions. The action taken is believed to play an important role in the effort to improve teaching and learning of variable measurements in quantitative research.
\end{abstract}

Keywords: action research, teaching and learning, challenge the challenger, variable measurements, enhancing quantitative research.

\section{Introduction}

Research methodology and statistical data analysis have always been the core subjects for university students. Through the observation of the researchers throughout the teaching process of these two courses, the researchers noted that students do not fully master the understanding and the application of quantitative measurements. The effect of this incompetency has affected their final year research. The lack of understanding of variable measurements such as nominal, ordinal, interval, and ratio has caused misapplication in the research conducted.

The researchers, who are also lecturers of Research Methodology as well as Quantitative Analysis courses, have taken this matter very seriously and are looking reasons for the students' incompetency. One of the actions taken was to conduct a quiz without telling the student or pop quiz to enhance the students' understanding regarding the four variable measurements as mentioned above. Without scientific research measurements, the action to hold a quiz in any teaching process has proven to be more effective than any method of lectures. However, that action was seen as a passive approach or one-way in the context of communication between lecturer and students. The loophole in the quiz approach is that students are merely waiting and predicting what the questions will be.

Although there were efforts to conduct a teaching intervention, researchers found that there is much space for improvement in learning among the students through a more interactive approach. Good learning and teaching management include strategy planning, implementation and application of techniques as well as evaluation management $(\mathrm{Ee}, 2006)$ where the ultimate aim of technique implementation or intervention is to improve the teaching and learning atmosphere. One teaching and learning technique that is common in corporate workshops is thought to be suitable for adult students and this technique is named as "challenge the challenger" by the 
researchers. It is suggested that students in this research take up the challenge to create group quiz questions and then challenge course mates from the opposing team to answer those questions. In this research lecturers mediate students' responses and refine questions throughout the implementation process and act as moderators in structuring the information and network system.

Generally, the objective of this research is to evaluate the effectiveness of the new techniques that are implemented. In this study, the action research aimed to:

a) Identify the effectiveness of "group quiz" technique and "challenge the challenger" intervention technique in enhancing the understanding regarding variable measurements; and

b) Identify whether the effect of improvisation "challenge the challenger" method is better than "group quiz" technique.

\section{Literature Review}

Current teaching educational practice is often associated with class management and pedagogical perspectives. However many teaching practitioners are not able to deliver effective teaching methods that students expect. They often deliver lectures without the appropriate activities to stimulate students' interest. Delivering the appropriate teaching and learning strategies are vital to ensure maximum input is delivered to students. Therefore there is a need to look at teachers teaching methods as students place high expectations of teachers teaching to get maximum knowledge. Thus this current study focuses on challenging students' mind in a quantitative research methodology class. Appropriate steps should be taken to improve students' achievement in any quantitative research method class. To achieve effective learning outcome, teachers must possess positive attitude and concrete teaching capabilities like having a strong background knowledge in the subjects they are teaching; identifying the appropriate teaching and learning theories, having the expertise to facilitate the teaching process and having the capabilities to implement positive teaching processes through effective interpersonal and interpersonal interaction amongst students, subsequently, increasing their learning interest and motivation.

This study focuses on the efforts to stimulate students' minds to respond to a challenge given in a quantitative teaching class. The most appropriate related theory proposed here is Lev Vygotsky's (1978) constructivism theory. Constructivism is a theory that explains how learning takes place to observe if students use past experience to understand lectures and to follow instructions in the process of building understanding. This theory promotes active learning where students not only absorb and store information, they also recall and interpret active experiences and give good personal opinions. This cognitive teaching approach allows teachers to emphasize how students use, accept, build and analyse knowledge seriously. Students who are actively involved can easily recall what they have learned. Therefore, constructivist learning intervention is a process where activities are employed contextually and students are given the opportunity to discover and construct meanings while the intervention process is taking place.

\subsection{Constructivist Learning Intervention}

\section{a) Students' Background}

Each and every student is unique and has a different background. Social constructivists encourage students to personally witness the realities of their surroundings which are culturally and personally influenced. Through social interaction students are able to interpret social meanings system symbols and learn how to use them. Their personal background helps them to form and understand knowledge gained during their early learning process. And it is during this early process students are seen to be actively involved and will form their personal understandings. After having the capabilities to interpret meanings, students will have the motivation and interest to observe and analyse meanings. Subsequently this relies on the students' self-confidence and self-competency available through practice and experience which is closely related to the proximal zones (Vygotsky, 1999). This concept challenges students to the closest proximal zones, meaning that they challenged one level higher from their current proximal development zone. Through experience, students are able to solve challenging tasks and gain more confidence and motivation to accomplish more complex tasks.

\section{b) Teachers' Role}

In a constructivist theory, the role of the teacher is merely a facilitator and not a teacher. It is vital to understand this concept as by nature a teacher normally teaches in a deductive form that encompasses subject content while a facilitator guides students towards understanding the content and students are actively involved in the second situation. Thus the interaction process is well focused on an active and interactive student-centered learning. A teacher tells and teaches but a facilitator questions; a teacher teaches in front of the class while a facilitator supports from the back; a teacher gives answers from the curriculum set while a facilitator guides and builds 
situations for students to build their conclusion; a teacher gives a monolog lecture while a facilitator creates a dialogue with students. The real motives in this kind of classroom are to allow students to be creative and critical thinkers.

\section{c) The Learning Process Situations}

Learning is an active and collaborative social process where students construct experience with a group. Constructivists believe that learning is an active process and students discover the principles, concepts and facts and deep thinking. In this situation, a dynamic teacher-student interaction is vital where they learn simultaneously from each other. This means that the learning experience is subjective as well as objective where culture, values and teachers' background become the main pillar in the students' interaction and tasks to build meanings. This leads to a basic understanding between teachers and students to form awareness in their individual opinion and compares with their personal believes, standards and values to be more subjective and objective. A dynamic relationship is an important element in an interactive learning situation.

d) Interacting through Challenging Students' Mind

Vygotsky (1978) said that students' minds should be consistently challenged with a high level skill-based and knowledge-based task in line with the Development Proximity Zones (Vygotsky, 1978) which is seen as the true development level (determined by free problem solving) and the potential development level. This kind of challenge is expected to motivate students from previous success to enhance their confidence. He further asserted that this learning style is able to enliven and bring out a functional set that has existed in the proximity zones. At this level, education plays a vital role in the development process of students. Ultimately, the students aim is focused towards what has been learnt.

In conventional learning, knowledge gained is often a one sided communication. The introduction of the quiz technique in class, has made teaching more flexible and fun. Lecturers discovered that this technique has elevated students' interests of the things they learned.

Usually, students are encouraged to access the source of learning in order to gain knowledge and skill independently. By doing that, students are taught the self-access learning concept thus allowing them to follow their own interests and to be always ready for an exam or quiz that will be held anytime. Generally, it is acknowledged that students need to be proactive in the self access learning process. (Fitzgerald, Morall \& Morrison, 2000).

According to the self-access learning concept, students should not be passive and only respond to teacher's stimulation (Boud, 1988; Kohonen, 1992; Knowles, 1975). They should instead be responsible for their own learning. According to Gardner and Miller (1996), autonomous students are students who have the initiative to plan and implement their own learning programme. In the context of self-access learning concept, lecturers function as facilitators and counsellors apart from taking main role as knowledge disseminator of a subject. This will surely need the shift of teaching and learning approach, that is, lecturer-centered to student-centered.

Based on the idea of self-access learning concept, these researchers are interested to provide students with the skills needed to master the concept of "learning how to learn." They should be challenged to prove their own capability and learn to take the appropriate action. "Challenge the challenger" teaching technique should be introduced in higher learning institutions to enhance teaching and learning quality.

\section{Methodology}

This research follows the action research cycle frame. As explained in the action research cycle forwarded by Ferrance (2000), five steps need to be observed. After identifying the problem statements as mentioned above, the researchers started to plan the process of data collection and organization. The next step is to interpret the data, to take action according to proof and to do reflection throughout the action.

UKM Communication undergraduates that are taking Research Methodology were identified as subject for this action research. 194 students taking the course during the same semester were used as sample for pioneer study. Among them, 100 students were from SKKP3043 Research Methodology class while the other 94 students were from SKKP2014 Communication Research Method class. They were made participants in this experiment case that involved different intervention. Kinder and Palfrey (1993) suggested that experiment quasi is very suitable to observe the effect brought by each intervention. In the context of this research, the intervention given was "challenge the challenger" technique and "group quiz" technique. Researchers did not plan to have a control group without intervention so as not to deprive the students' enhancement in learning.

Based on Diagram 1, the students were divided into two groups where 100 SKKP3043 students were planning to 
go through the "challenge the challenger" intervention and 94 SKKP2014 students were planning to go through the "group quiz" intervention. This division is significant to avoid the effect of time lag.

Students' level of understanding regarding the four types of quantitative data measurements is the measurement for this experiment quasi. Pre and post test score for both groups were taken and compared to observe the differences. Pre-test instrument involved four subjective questions that were given 25 percent for each question and 10 objective questions that were given 10 percent for each question. Instrument for post-test added four subjective questions and 10 new objective questions. Therefore, for the post test instrument, eight objective questions were given a percentage of 12.5 for each question and 20 objective questions given a percentage of 5 for each question. The maximum score for both pre and post-test was 100. The questions have been used prior to this test to ensure the validity of the instrument in this research.

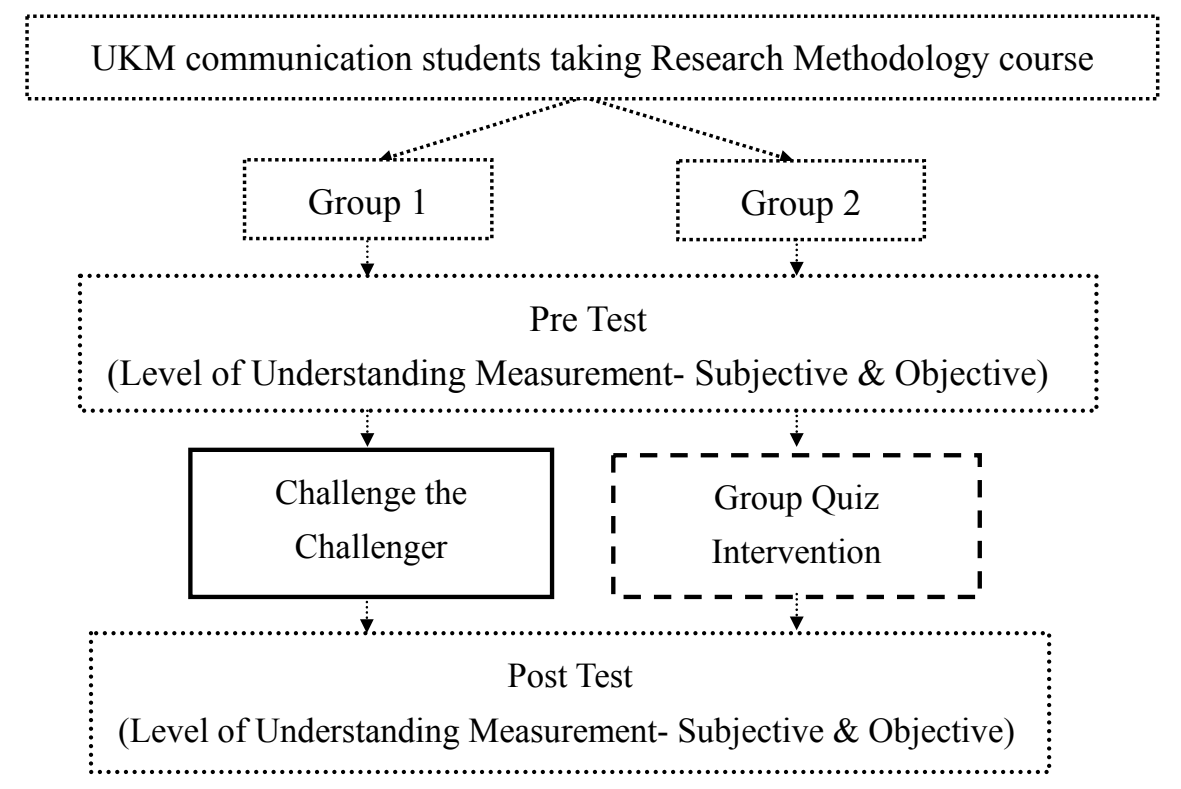

Figure 1. Research framework

Pretest was done a week after the students were taught about the four types of measurement mentioned above. SKKP2014 students sat for the pre-test on 29th July 2009 while SKKP 3043 students sat for the test on 31st July 2009. Students were informed about the "group quiz" and the "challenge the challenger" activity during tutorials; one day and three days after pre-test respectively. SKKP2014 students were told to conduct a group quiz competition a week after that. SKKP 3043 students meanwhile were told to discuss with their group members to create quiz questions to compete with the opposing group a week after that. In other words, "challenges the challenger" activity conveys the idea of accepting the challenge to create questions in the initial stage and to challenge the other group to answer the questions at a later stage. Self access learning concept with the cooperation of the group members was channeled to "challenge the challenger" group.

Each intervention was done on the 6th and 10th of August in the same year during tutorial classes. As soon as the "group quiz" and "challenge the challenger" intervention was done, students who participated are given a survey form to state comments and suggestions to the learning methods that are not conventional and not commonly applied. Nearly a month after intervention, post test was made to gauge the level of students' understanding as well as memory retention. The test was done in each class's lecture hall about a month later on 2nd and 4th of September respectively.

To achieve the specific objectives of this research, data collected were divided into objective and subjective sections to be used in testing the effect changes to answer the following research questions:

RQ1 : Is there a significant improvement of understanding after both interventions of "group quiz" and "challenge the challenger" techniques?

RQ2: Is "challenge the challenger" technique more effective than "group quiz" technique? 


\section{Findings}

Even though 194 students were identified, only 143 students were involved in all three stages of this research the pre-test, intervention and post-test. The data were successfully collected from 68 students from "challenge the challenger" intervention group with a participation rate of 68 percent and 75 students from the "group quiz" group with a participation rate of 80 percent.

Statistical analysis is more suitable than the Split-Plot and Repeated Measures Analysis of Variance method. SPSS application that produced General Linear Model can help with the data analysis. Box test for both subjective and objective sections produced $\mathrm{p}>.05$ which is not significant and this shows that the manipulated variable covariant across the variable groups is the same. This also shows that the covariant value similarity condition must be followed. Meanwhile Sphericity test need not be conducted since there are only two repetitive measurements.

In the pre-test for subjective section, the "challenge the challenger" group gets a low mean score with $\mathrm{M}=18.09$ $(\mathrm{SD}=15.41)$ compared to the "group quiz" that obtained $\mathrm{M}=25.27$ ( $\mathrm{SD}=20.70)$. Significant $t$ test difference $(135.99)=2.367, p=.019$ shows that they are not homogenous. For the objective section, both groups were homogenous whereby the mean score for "challenge the challenger" $\mathrm{M}=34.12(\mathrm{SD}=21.32)$ and "group quiz" $\mathrm{M}=34.80(\mathrm{SD}=17.96)$ with $\mathrm{t}(141)=.028, \mathrm{p}=.836$, which is not significant. The mean score for both groups in pre and post-test is presented in Table 1. Findings presentation starts with the subjective section followed by the objective section.

Table 1. Mean score of Measurement Understanding

\begin{tabular}{lrrrrrr}
\hline \multirow{2}{*}{ Intervention } & \multicolumn{2}{c}{ Subjective Section } & \multicolumn{4}{c}{ Objective Section } \\
& Pre Test & Post Test & \multicolumn{2}{c}{ Pre } & Post Test & N \\
& \multicolumn{4}{c}{ Test } \\
Challenge the & 18.09 & 47.32 & 34.12 & $(21.32)$ & 54.93 & 68 \\
Challenger & $(15.41)$ & $(17.68)$ & & & $(17.05)$ & \\
Group Quiz & 25.27 & 35.23 & 34.80 & $(17.96)$ & 49.47 & 75 \\
& $(20.70)$ & $(17.25)$ & & & $(19.55)$ & \\
\hline Total & 21.85 & 40.98 & 34.48 & $(19.56)$ & 52.06 & 143 \\
& $(18.66)$ & $(18.42)$ & & & $(18.54)$ & \\
\hline
\end{tabular}

Note: Value in bracket represents standard deviation

Each group's mean score was observed to answer the first objective question to identify the effectiveness of both interventions that were applied. "Group quiz" group increased from $\mathrm{M}=25.27(\mathrm{SD}=20.70)$ to $\mathrm{M}=35.23$ ( $\mathrm{SD}=$ 17.25), while "challenge the challenger" increased from $\mathrm{M}=18.09$ ( $\mathrm{SD}=15.41)$ to $\mathrm{M}=47.32(\mathrm{SD}=17.68)$. Value of difference test $\mathrm{F}(1,141)=100.838, \mathrm{p}=.000$ proving there was a significant increase in understanding over all of the subjective section. Statistic test value is conveyed in Table 2. In the same table, difference test value $\mathrm{F}(1,141)=24.352, \mathrm{p}=.000$ is presented to see the effect of interaction in understanding increment. The results of the second research question revealed that "challenge the challenger method" is proven to be more effective than "group quiz" for the subjective section.

Table 2. Difference test in subject

\begin{tabular}{lrrrrr}
\hline Source & SS & Df & MS & $F$ & $P$ \\
\hline Subjective Section: & & & & & \\
$\quad$ Understanding (Pre-Post) & 27394.084 & 1 & 27394.084 & 100.838 & .000 \\
$\quad$ Interaction & 6615.675 & 1 & 6615.675 & 24.352 & .000 \\
(Understanding*Intervention) & & & & & \\
$\quad$ Error & 38304.692 & 141 & 271.664 & & \\
Objective Section: & & & & & \\
$\quad$ Understanding (Pre-Post) & 22441.969 & 1 & 22441.969 & 67.507 & .000 \\
\hline
\end{tabular}




\begin{tabular}{lrrrrr}
\hline $\begin{array}{l}\text { Interaction } \\
\text { (Undestanding*Intervention) } \\
\text { Error }\end{array}$ & 672.738 & 1 & 672.738 & 2.204 & .157 \\
\hline
\end{tabular}

Referring to Table 1 and comparing Mean Score in objective section, "group quiz" increased from $\mathrm{M}=34.80$ $(\mathrm{SD}=17.96)$ to $\mathrm{M}=49.47(\mathrm{SD}=19.55)$ while "challenge the challenger" increased from $\mathrm{M}=34.12(\mathrm{SD}=$ $21.32)$ to $\mathrm{M}=54.93(\mathrm{SD}=17.05)$. In Table $2, \mathrm{~F}(1,141)=67.507, \mathrm{p}=.000$ proved that there was a significant improvement of understanding of the whole of the objective section. However, F $(1,141)=2.204, p=.157$ had failed to reject the null hypothesis that said the effect of both interventions is the same. "Challenge the challenger" technique can't be said to be more effective than "group quiz" for objective section.

In conclusion, both interventions proved to be effective in both the subjective and objective question sections. The result proved that the extra learning method increased students' understanding and memory. Comparison between both interventions showed only in the subjective section that "challenge the challenger" technique is more effective than "group quiz".

\section{Discussion and Summary}

This action research was conducted in the effort to identify the effectiveness of "challenge the challenger" and "group quiz" intervention in increasing the level of understanding variable measurements. The conclusion of the findings presentation has fulfilled the purpose of this research.

From the mean score of the objective and subjective question sections, intervention effectiveness can be discussed. In the subjective section, "challenge the challenger" group obtained $\mathrm{M}=18.09$ ( $\mathrm{SD}=15.41)$ during the pre test and was observed to be lower than the "group quiz" group that obtained $\mathrm{M}=25.27(\mathrm{SD}=20.70)$. Thus, this is a limitation from the aspect of not starting from the same base. However, during the post test, "challenge the challenger" group increased 29.23 scores to $\mathrm{M}=47.32$ ( $\mathrm{SD}=17.68)$, while "group quiz" only increased 9.96 scores to $\mathrm{M}=35.23(\mathrm{SD}=17.25)$. This state is clearly shown in the profile plot in Diagram 2 where the line inclination is steeper for "challenge the challenger" group. This shows that "challenge the challenger" intervention is proven to be more interactive and is able to enhance student's talent and capability in answering the subjective questions.

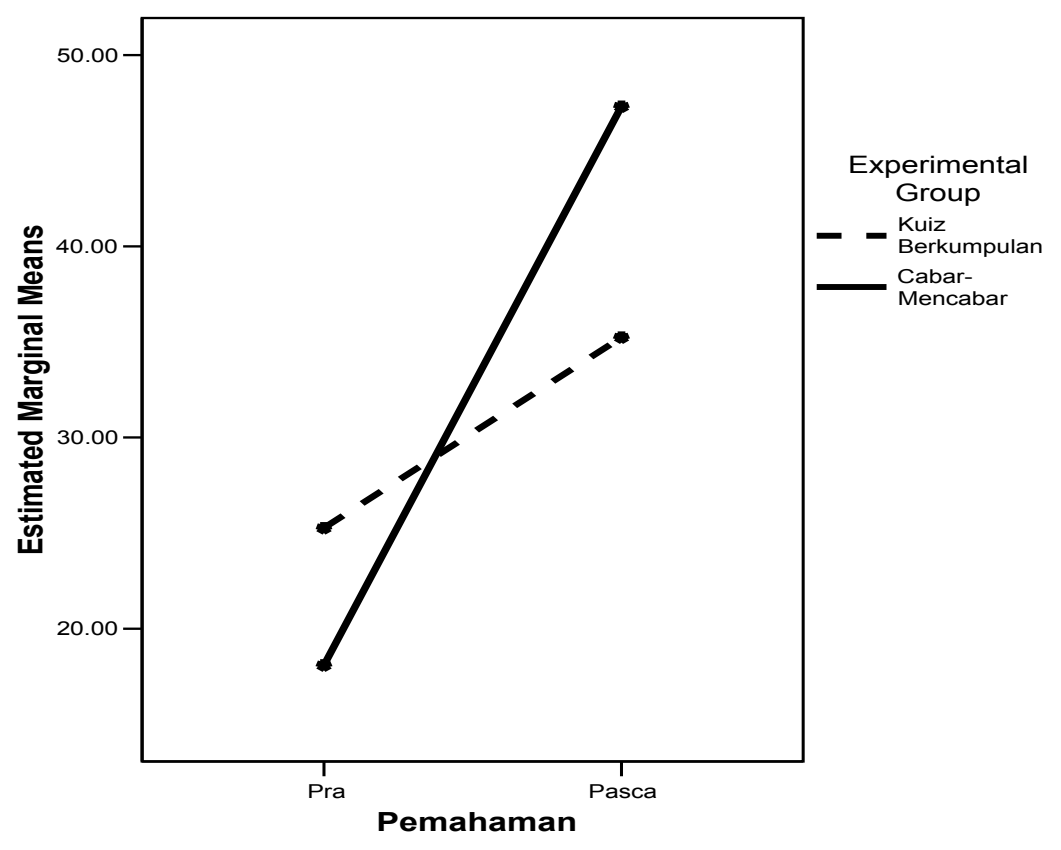

Figure 2. Profile plot of subjective section

Meanwhile, for the objective section, both groups started with a balanced base whereby the mean score for 
"challenge the challenger" $\mathrm{M}=34.12(\mathrm{SD}=21.32)$ is compared to "group quiz" $\mathrm{M}=34.80(\mathrm{SD}=17.96)$. Results reveal that "Challenge the challenger" group shows an increased by 20.81 score to $\mathrm{M}=54.93$ (SD = $17.05)$ and "group quiz" increased from 14.67 score to $\mathrm{M}=49.47(\mathrm{SD}=19.55)$. Difference of score increment is not of clear significance and the profile plot in Diagram 3 shows the inclination of both lines are more or less the same.

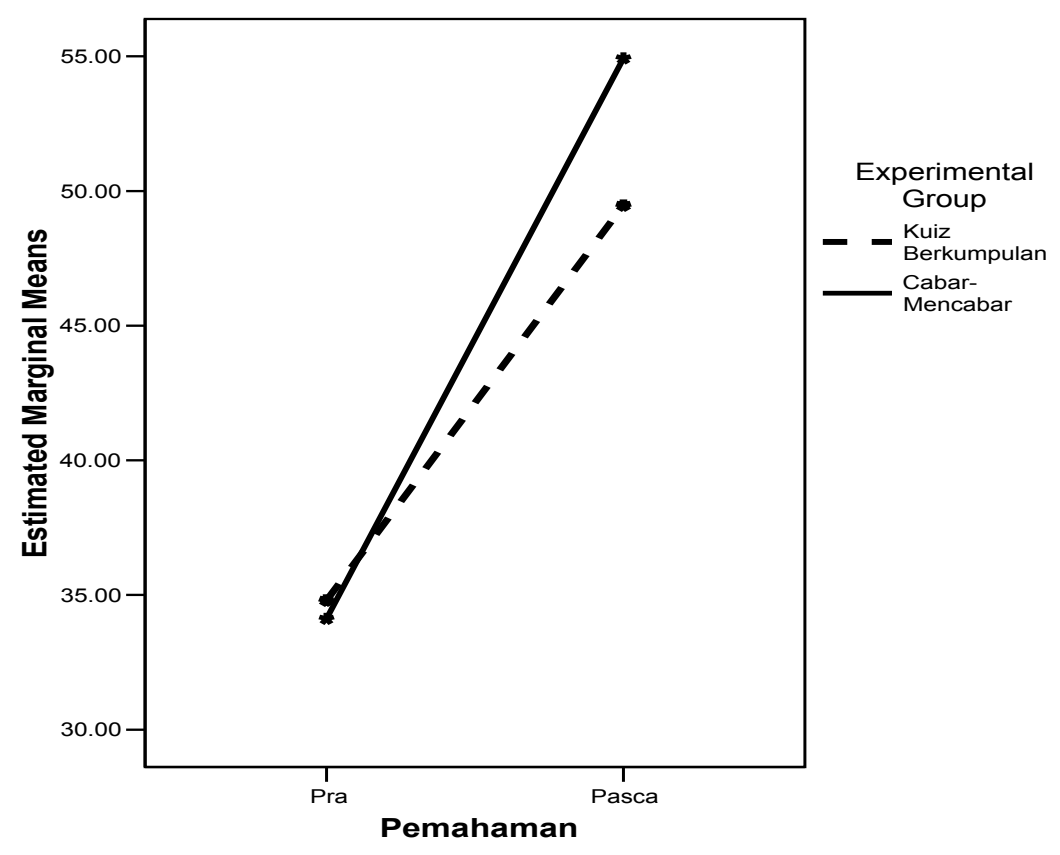

Figure 3. Profile plot of objective section

The researcher's analysis of comments and suggestions by both groups after the post-test revealed that almost all students gave positive responses that are very encouraging regarding the activities that implemented. It is found that these activities are more interesting and have enhanced the students' understanding regarding statistic variable measurement level. Besides that, students from "challenge the challenger" group stated that this activity was useful for them and can be applied in the learning of other subjects and also to "improve" their memories, that is to overcome their weakness in memorization. This effect came from preparing questions for other groups, because the lecturers who are involved in constructing the questions are required to first understand the concept that will be questioned. They also stated that this new learning method is collaborative and encouraged the students to be more proactive among themselves and indirectly, transferring the learning autonomy from lecturers to students. This response is similar to self-effort strategy initiated by Fitzgerald et al. (2000) in self access learning. This kind of new students' role can incite students' interest to think critically and creatively.

To sum up, "challenge the challenger" and "group quiz" intervention were successfully measured through the comparison of the student's understanding of variable measurements before and after intervention. The action taken was very important especially in an effort to enhance teaching and learning of variable measurements in quantitative research. Suggestion for the next action is to identify the effectiveness of these interventions in the application and problem solving process.

\section{References}

Boud, D. (1988). Developing student autonomy in learning. New York: Kogan Page.

Ee Ah Meng. (2006). Penilaian tahap kecekapan: Kompetensi khusus (fungsi) pengurusan P\&P (2nd ed). Shah Alam: Oxford Fajar.

Ferrance, E. (2000). Action research. Providence: Laboratory At Brown University.

Fitzgerald, S., Morall, A., \& Morrison, B. (2000). Catering for individual learning styles: Experiences of orienting students in an Asian self-access centre. Retrieved from http://elc.polyu.edu.hk/CILL/staff/auto200.htm 
Gardner, D., \& Miller, L. (1996). Tasks for independent language learning. Virginia: TESO.

Greeno, J. G., Collins, A. M., \& Resnick, L. B. (1996). Cognition and learning. In D. C. Berliner, \& R. Calfee (Eds.), Handbook of educational psychology (pp. 15-46). New York: Macmillan. http://dx.doi.org/10.1037/0278-7393.22.3.687

Holt, D. G., \& Willard-Holt, C. (2000). Let's get real - students solving authentic corporate problems. Phi Delta Kappan, 82(3).

Kinder, D. R., \& Palfrey, T. (1993). Experimental foundation of political science. Ann Arbor: University of Michigan Press.

Knowles, M. (1975). Self-directed learning. New York: Association Press.

Kohonen, V. (1992). Experiential language learning: Second language learning as cooperative learner education. In Nunan, D. (Eds.), Collaborative language learning and teaching (pp. 14-39).

Vygotsky, L. (1978). Mind and Society (Trans. M. Cole). Cambridge, MA: Harvard University.

Vygotsky, L. (1997). Interaction between learning and development. In Gauvin, M., \& Cole, M. (Eds.), Readings on the development of children (pp. 29-36). 